\title{
Trihalomethane Formation Potential in Surface Water of Kanpur, India
}

\author{
NIDHI DIXIT MISHRA and SATISH CHANDRA DIXIT*
}

Department of Chemistry, D.B.S. (Post-graduate) College, Kanpur-208006, India

satishdixit1@gmail.com

Received 11 December 2012 / Accepted 13 January 2013

\begin{abstract}
To study the formation potential of trihalomethanes (THMs) due to anthropogenic sources and effect of various precursors on potential of THM formation, surface treated water samples were collected from Ganga Barrage Water Treatment Plant, Kanpur $\left(26^{\circ} 26^{\prime} \mathrm{N}, 80^{\circ} 20^{\prime} \mathrm{E}, 142 \mathrm{~m}\right.$ altitude from mean sea level), India from January to June 2009. In May and June, all the THMs were identified. Trihalomethane formation potential (THMFP) values in May and June were found to be three times higher than those in January. The concentration of THM species was found to increase with chlorine dosages. The higher the reaction time leads to higher chloroform concentrations which is very prominent for higher chlorine dosages. DCBM (dichlorobromomethane), BF (bromoform) and DBCM (dibromochloromethane) concentrations were nearly independent of the reaction time for more than $24 \mathrm{~h}$ for each considered chlorine dosage. With increase in chlorine dosages, the values of THMFP increased as the TOC (total organic carbon) increased except February.
\end{abstract}

Keywords: Trihalomethanes, Surface treated water, Chlorine dosage, Reaction time, Total organic carbon, Gas chromatograph

\section{Introduction}

Often, surface water is reported to contain organic matter derived from both natural degradation of some organic substances within the ecological systems and from anthropogenic activities. The introduction of water chlorination as standard treatment technique caused a large drop in mortality from infectious diseases ${ }^{1}$ and is considered as one of the major public health advances in the twentieth century. In 1976, the US National Cancer Institute ${ }^{2}$ published results showing that chloroform, one of the trihalomethanes (THMs) that occurs as a by-product of drinking water disinfection, was an animal carcinogen $^{3}$. Ever since there has been a concern that disinfection of water, while providing protection against microbial risks, could also pose chemically induced cancer risks for humans ${ }^{4}$. Chlorination leads to the formation of potentially harmful by-products (called disinfection by-products or DBPs). Chlorination DBPs are considered potentially carcinogenic ${ }^{5}$ and have been associated with adverse reproductive outcomes following exposure during pregnancy ${ }^{6,7}$. THMs are the most important group of DBPs. THMs include chloroform, dichlorobromomethane (DCBM), dibromochloromethane (DBCM) and bromoform (BF). Organic matter in natural water is considered as the dominant THM precursor in drinking water ${ }^{8}$. 
The total organic carbon (TOC) concentration of water is generally an indicator of the amount of THM precursor present ${ }^{9.10}$. In addition to natural organic matter (NOM), the sources of THM precursors may also be attributed to pollutant discharge such as domestic sewage, industrial effluent and agricultural drains ${ }^{11-13}$. Most of the organic pollutants interact with chlorine to produce DBPs during disinfection ${ }^{14}$. The major THM precursors appear to be aquatic humic substances ${ }^{9,15-17}$. Properties of THM precursors are site-specific, as the organic matter isolated from various sources does not exhibit the same THM formation potential ${ }^{18}$. The character and properties of NOM differ considerably in waters of different origins and depend on the biochemical cycles of the surrounding environments ${ }^{19}$. More ever, the range of organic components of NOM may also vary in the same location seasonally ${ }^{20,21}$. Marhaba et al. ${ }^{22,23}$ studied NOM and THMFP generally in water for drinking water facilities. In many developing countries, raw sewage discharge into the surface water without any treatment often causes serious drinking water quality problems ${ }^{24}$. Yoon et al. ${ }^{25}$ investigated the characteristics of THMs formation in five major river water in Korea. Zhao et al. ${ }^{26}$ collected water samples from Guangzhou section of the Pearl river to investigate soluble organic fractions and formation of THMs after chlorine and chlorine dioxide treatments. Xue et al. ${ }^{27}$ studied THMFP and structural characteristics of DOM (dissolved organic matter) in the secondary effluent from the Wenchang Waste Water Treatment Plant (Harbin, China). Chen et al. ${ }^{28}$ evaluated the impact of treated waste water discharge on downstream water quality in an effluent-dominated stream in the South-West USA. Studies conducted on mammals revealed that THMs induce neurotoxicity, hepatotoxicity, reproductive toxicity and nephrotoxicity ${ }^{29}$. In general, the brominated DBPs are both genotoxic and carcinogenic than are chlorinated compounds ${ }^{30}$. $\mathrm{WHO}^{31}$ has regulated the health related guideline values $(\mathrm{GV})$ for such compounds in drinking water (Table 1).

Table 1. WHO guideline values for drinking water quality ${ }^{31}$

\begin{tabular}{ccl}
\hline Disinfection by-products & Guideline Values, $\mu \mathrm{g} / \mathrm{L}$ & \multicolumn{2}{c}{ Remarks } \\
\hline Trihalomethanes & - & $\begin{array}{l}\text { The sum of the ratio of the } \\
\text { concentration of each to its respective } \\
\text { guideline value should not exceed 1 }\end{array}$ \\
\hline Bromoform & 100 & \\
Chlorodibromomethane & 100 & \\
Bromodichloromethane & 60 & \\
Chloroform & 300 & \\
\hline
\end{tabular}

Literature review provides very scarce information regarding THM formation in Indian conditions. Kanpur $\left(26^{0} 26^{\prime}\right.$ N, $80^{\circ} 20^{\prime}$ E, 142 m altitude from mean sea level) was once known as "Manchester of the East" is the industrial capital of the state of Uttar Pradesh (India) has been chosen as the study site for analysing THMs in drinking water as this is the region where fast urbanization and heavy population growth is going on and which is the hub of heavy industries. Its population is over four million and is situated on the bank of sacred Himalayan River Ganges which provides drinking water to the city. The river Ganga, which is lifeline to the north India, is exposed to the toxic drainage from industries, municipal sewage and agricultural drains. More ever, water supply in the stream has also reduced due to construction of hydroelectric projects and canals in the higher reaches. Condition becomes worse during summer. The surface treated water (water just before disinfection) samples were collected from Ganga Barrage Water Treatment Plant, Kanpur (India) from January to June 2009 to study the formation potentials of THMs due to anthropogenic sources and effect of various precursors on the potential of THM formation. 


\section{Experimental}

All chemicals used were of the analytical reagent grade unless specified otherwise. High purity gas was used for various experimental purposes. De-ionized water obtained from a Milli-Q system (Millipore, USA) was used for all experimental purposes.

\section{Glassware}

Borosilicate glass (ASTM type-I, Wheaton Science, Millville, NJ, USA) vials of $40 \mathrm{~mL}$ equipped with screw caps having Teflon faced re-sealable septa were used. The $1 \mathrm{~L}$ capacity reagent bottles to preserve the chlorinated samples and $300 \mathrm{~mL}$ reagent bottles to quench the samples were also made of borosilicate glass. Micro syringes (Hamilton, USA) of $10 \mu \mathrm{L}, 50 \mu \mathrm{L}$, $100 \mu \mathrm{L}, 500 \mu \mathrm{L}$ and $1000 \mu \mathrm{L}$ were used during the experiments. Before use, glassware were acid washed, followed by rinsing with tap water, distilled water and then dried in an oven at $180{ }^{\circ} \mathrm{C}$.

\section{Treated water samples and sampling schedule}

Treated water (water just before disinfection) samples were collected from Ganga Barrage Water Treatment Plant, Kanpur (India) (capacity: 200 millions of litres per day) in sampling cans downstream of the rapid filtration unit in the first week of every month from January to June 2009 and carefully transported to the laboratory. Treated water samples were stored at $4{ }^{\circ} \mathrm{C}$.

All the experiments were completed with utmost precaution and Standard Methods ${ }^{36}$ was referred to conduct experiments unless otherwise specified. In a typical experiment, treated water samples were chlorinated with 4 different chlorine doses each. The free chlorine residuals (FCR) and combined chlorine residuals (CCR) were measured for each sample and at each chlorine dose applied. THMs (4 compounds) concentrations were measured at 3 different contact times after chlorination. The formation potentials (FP) for the above compounds were measured 7 days after chlorination. UV absorbance@254 nm, bromide concentration and total organic carbon (TOC) were also measured for all water samples.

\section{Preliminary experiments}

Pure compounds (THMs and the internal standard) were diluted to required concentrations using MTBE. Five point calibration curves were prepared for GC for all the 4 THMs. All the curves were linear in nature. Extraction efficiencies for all the compounds were checked prior to the actual experiments and calibration curves were redrawn if recoveries were not found in the range of $90-110 \%$. Standard calibration curves were also prepared for TOC analyzer and Ion chromatograph (IC) to analyze total organic carbon and bromide concentration of water samples.

\section{Chlorine application}

A stock solution of sodium hypochlorite $(1000 \mathrm{mg} / \mathrm{L})$ was prepared. As a preliminary exercise, treated water samples were chlorinated with different doses and the chlorine demand of the samples was determined using FAS/DPD titration method. Four dosages were finalized such that there was enough free chlorine residual after $30 \mathrm{~min}$ of chlorination. Four aliquots of treated water were taken in $1 \mathrm{~L}$ capacity reagent bottles. Hypochlorite solution was added to these bottles to achieve the required chlorine concentration. The bottle contents were mixed and stored at $20^{\circ} \mathrm{C}$. Chlorine residuals (FCR, CCR) were measured after $30 \mathrm{~min}$ of chlorination using FAS/DPD titration.

\section{Extraction of THMs}

Samples were extracted in duplicate for THM determination. For a typical extraction, after specified contact time, a $50 \mathrm{~mL}$ aliquot was used. Sodium sulfite was added to the aliquot to 
quench the available free chlorine before extraction. EPA method 551.1 was adapted for extraction of THMs. Liquid-liquid extraction method has been used for the determination of THMs in aqueous samples.

\section{Analytical techniques}

Various water quality parameters such as bromide ion concentration, total organic carbon, $\mathrm{UV}_{254}$ absorbance, $\mathrm{pH}$ and alkalinity were determined by standard procedures. Extracts of THMs were analyzed using Gas Chromatograph.

\section{Water quality analysis}

The concentration of dissolved organic carbon was detected with a TOC analyzer (Model: TOC-5000A, Shimadzu, Japan). The $\mathrm{pH}$ of water samples was measured using a combination $\mathrm{pH}$ electrode (Toshniwal CL-51, India) connected to a digital $\mathrm{pH}$ meter (Toshniwal CL-54, India). The alkalinity was deduced from inorganic carbon and $\mathrm{pH}$ values of the water samples. The concentration of bromide ion was measured by Ion Chromatograph (Model: 761 compact IC, Met Rohm, USA). UV absorbance at $254 \mathrm{~nm}$ $\left(\mathrm{UV}_{254}\right)$ was measured with a spectrophotometer (UV-VIS, Varian, USA).All chromatographic analyses were performed using a Gas Chromatograph equipped with an electron capture detector (Model: 910, Buck Scientific, USA).

\section{Results and Discussion}

Surface treated water samples were collected from the Ganga Barrage Water Treatment Plant, Kanpur (India) on a monthly basis for six months from January to June 2009. The various water quality parameters measured in each samples were: $\mathrm{pH}, \mathrm{TOC}, \mathrm{UV}_{254}$, alkalinity and bromide and are tabulated in Table 2 . The samples were chlorinated at various dosages and corresponding free chlorine residual (FCR) and combined chlorine residual (CCR) values were measured. Further, concentrations of various THM species in the said water samples were determined at different times corresponding to each chlorine dose.

Table 2. Surface treated water quality parameters

\begin{tabular}{lcccccc}
\hline \multicolumn{1}{c}{ Water quality } & January & February & March & April & May & June \\
parameters & 2009 & 2009 & 2009 & 2009 & 2009 & 2009 \\
\hline TOC, mg/L & 2.97 & 3.67 & 3.71 & 11.21 & 11.22 & 11.9 \\
$\begin{array}{l}\text { Alkalinity } \\
\text { (as } \mathrm{CaCO}_{3} \text { ), mg/L }\end{array}$ & 198 & 201 & 202 & 204 & 204 & 204 \\
Bromide, mg/L & 0 & 0.1 & 0 & 0.1 & 0.7 & 1 \\
pH & 7.5 & 7.5 & 7.6 & 7.6 & 7.6 & 7.4 \\
SUVA & 2.3 & 2.7 & 2.5 & 2.42 & 2.72 & 2.77 \\
\hline
\end{tabular}

\section{Trihalomethane formation potential}

The THMFP values at $5 \mathrm{mg} / \mathrm{L}$ chlorine dose were: $61.9,121.3,137.4,211.2,215.2$ and $230.6 \mu \mathrm{g} / \mathrm{L}$, respectively. In January only CF, in February, CF and DCBM, in March only $\mathrm{CF}$, in April DCBM and CF, in May and June all the THMs were identified (Figure 1a). All the values were below the WHO GV. The total THMs levels (sum of the ratio of the concentrations of each THM to its respective GV) of Jan., Feb and Mar. samples were below and April, May and Jun. samples were above the WHO GV of $\leq 1$. At $6 \mathrm{mg} / \mathrm{L}$ chlorine dose, the THMFP values were 77.6, 195.8, 146, 234.5, 247.3 and $259.64 \mu \mathrm{g} / \mathrm{L}$, respectively. In Jan. CF, in Feb. DCBM and CF, in Mar. only CF, in April DCBM and CF, in May and June all 
the THMs were identified (Figure 1b). All the values were below the WHO GV. The total THMs levels were above the WHO GV of $\leq 1$ except Jan. and Mar. samples. At $7 \mathrm{mg} / \mathrm{L}$ chlorine dose, the THMFP values were 109.3, 207.2, 158, 256.7, 278.1 and $295.6 \mu \mathrm{g} / \mathrm{L}$, respectively. In Jan. and Mar. CF, in Feb and April DCBM and CF, in May and June all the THMs were identified (Figure 1c). All the values were below the WHO GV. The total THMs levels were above the WHO GV of $\leq 1$ except the samples of January and March.
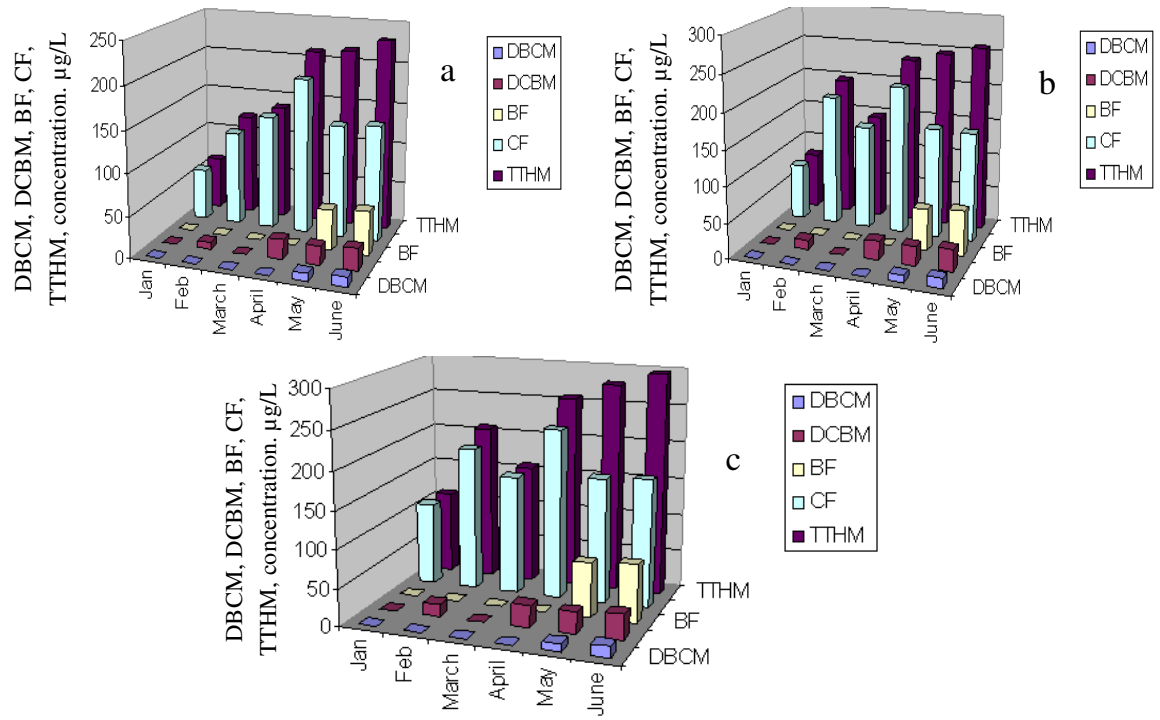

Figure 1. Temporal variations of the THMs concentrations in surface treated water for different chlorine doses (a) $5 \mathrm{mg} / \mathrm{L}$ (b) $6 \mathrm{mg} / \mathrm{L}$ (c) $7 \mathrm{mg} / \mathrm{L}$

\section{Seasonal variations in THMFP}

THMFP values in May and June were found to be three times higher than those in $\mathrm{Jan}^{32}$ (Figure 2). There was abrupt rise in the values of THMFP in the month of Feb. This might be because of the rapid decay of vegetation (a source of NOM in water) during spring ${ }^{33}$. Among individual THM species, the chloroform levels were found higher than DCBM, DBCM and bromoform in all the seasons (Figure 1a,b,c). The seasonal variation of chloroform concentrations reported the levels lower than the WHO GV except in April at $6 \mathrm{mg} / \mathrm{L}$ and $7 \mathrm{mg} / \mathrm{L}$ chlorine dosages.

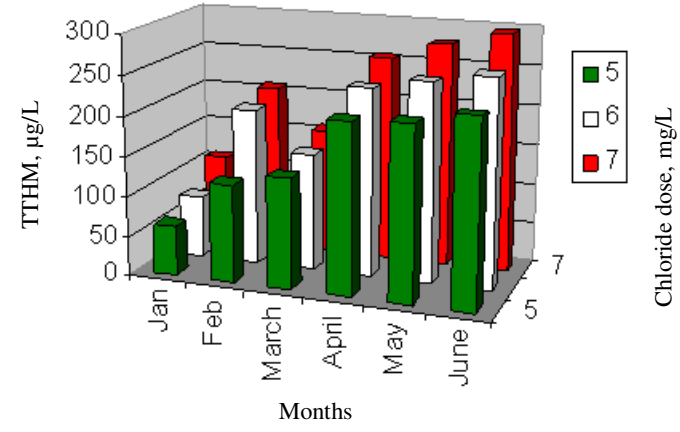

Figure 2. Seasonal variation in THMFP in surface treated water at different chlorine doses 


\section{Relationship between reaction time and THMFP}

Investigation was conducted to examine the relationship between the varying reaction time $(\mathrm{t}=4,8,24,168 \mathrm{~h} ; 168 \mathrm{~h}$ reaction time represents the formation potential) and varying chlorine dosages with the THM formation in the water samples. The studies revealed that the THM formation rate was very fast in the first $24 \mathrm{~h}$ compared to that of the exceeding reaction time ( $>24 \mathrm{~h}$ ). The concentrations of THM species were found to increase with chlorine dosages. The higher the reaction time leads to the higher chloroform concentration which was very prominent for higher chlorine dosages. DCBM, BF and DBCM concentrations were nearly independent of the reaction time for more than $24 \mathrm{~h}$ for each considered chlorine dose. The values of THMFP showed rising pattern with increasing chlorine dosages.

\section{Temporal variations of THMFP}

For chlorine dose $5 \mathrm{mg} / \mathrm{L}$, the values of THMFP showed the ascending trend from January to June as an outcome of temperature rise. For chlorine dosages $6 \mathrm{mg} / \mathrm{L}$ and $7 \mathrm{mg} / \mathrm{L}$, the THMFP values showed ascending trend from January to June with the exception of February (Figure 1a,b,c). The exceptionally high THMFP value in February might be attributed to the rapid decay of vegetation (a source of NOM in water) during spring. The concentrations of chloroform in May and June were found to be two times higher than those in January which clearly show the increased temperature impact (Jan.temp $15{ }^{\circ} \mathrm{C}$, May\& June temp $45^{\circ} \mathrm{C}$ ).

\section{Effect of bromide concentration on THMFP}

At different chlorine dosages $(5 \mathrm{mg} / \mathrm{L}, 6 \mathrm{mg} / \mathrm{L}$ and $7 \mathrm{mg} / \mathrm{L})$ in the months of February and April, only one Br-THM namely DCBM was formed while in the months of May and June, all the three Br-THMs were formed. This show that treatment of the raw water was not properly carried out in the treatment plant. Conventional biological sewage treatment process cannot remove the bromide ion. Bromide can be oxidized to bromine during chlorination. In competition between bromine and chlorine, the former may have the priority to react with $\mathrm{NOM}$ and thus result in a relatively high concentration ${ }^{34}$ of $\mathrm{CHBrCl}_{2}$. When bromide is present in raw water, even at trace levels, it can be oxidized to hypobromous acid $(\mathrm{HOBr})$ by hypochlorous acid $(\mathrm{HOCl})$. $\mathrm{HOBr}$ is believed to be a more powerful halogenating agent than $\mathrm{HOCl}$, although $\mathrm{HOCl}$ is a stronger oxidizing agent $^{35}$. The reaction incorporating bromine into NOM could take place at a higher degree and a faster rate than the incorporating chlorine ${ }^{36}$. Therefore, the presence of $\mathrm{Br}^{-}$in raw water could significantly increase its THMFP. In the months of April, May and June higher values of THMFP might be due to the incorporation of bromine into organic matter and reduction of TOC in the treated water.

\section{Effect of chlorine dosages on THMFP}

On investigating the samples, it was observed that as the chlorine dosages enhanced, the values of the THMFP also increased (Figure 1) with the exception of February which showed the abrupt rise.

\section{Effect of Total organic carbon (TOC) on THMFP}

It was observed that with the increase in the chlorine doses, the values of THMFP increased as the TOC increased with the exception of February (Figure 3). Reduction of TOC cause a higher $\mathrm{Br} / \mathrm{TOC}$ ratio and lead to high Br-THM and total concentration. This might be the reason for abrupt elevation of THMFP value in the month of February 2009. 


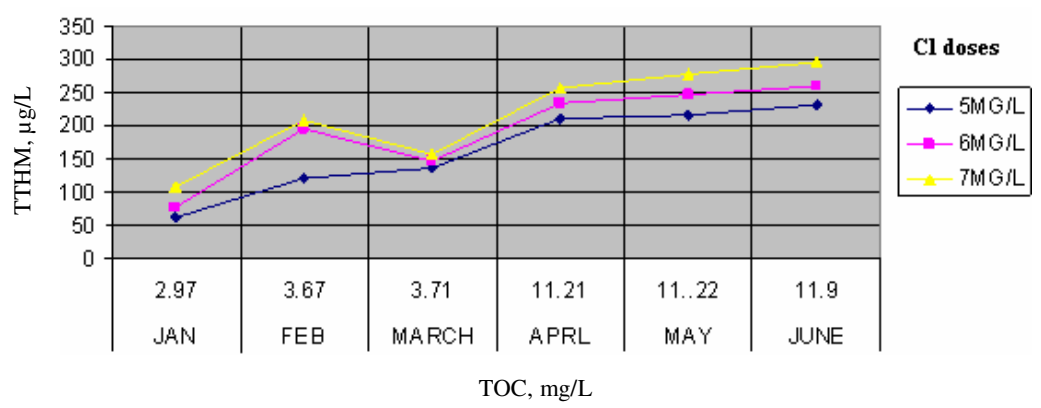

Figure 3. The effect of TOC on THMFP in surface treated water at different chlorine doses

\section{Conclusion}

In the surface treated water samples at $6 \mathrm{mg} / \mathrm{L}$ chlorine dosage, in Jan. only chloroform (CF), in Feb. CF and DCBM, in Mar. only CF, in April CF and DCBM, in May and June all the THMs were identified. All the values were below the WHO GV. The total THMs levels of Jan., Feb and March samples were below and April, May, and June samples were above the WHO GV $\leq 1$. At $6 \mathrm{mg} / \mathrm{L}$ chlorine dose, in Jan. CF, in Feb. CF and DCBM, in March CF, in April CF and DCBM, in May and June all the THMs were identified. All the values were below the WHO GV. The total THMs levels were above the WHO GV $\leq 1$ except Jan. and March. At $7 \mathrm{mg} / \mathrm{L}$ chlorine dosage, in Jan and March CF, in Feb and April CF and DCBM, in May and June all the THMs were identified. All the values were below the WHO GV. The total THMs levels were above the WHO GV $\leq 1$ except Jan. and March.

THMFP values in May and June were found to be three times higher than those in Jan. Among individual THM species, the chloroform levels were found higher than DCBM, $\mathrm{DBCM}$ and $\mathrm{BF}$ in all the seasons. The seasonal variation of chloroform concentrations reported the levels lower than the WHO GV except in April at $6 \& 7 \mathrm{mg} / \mathrm{L}$ chlorine dosages. THM formation rate was found to be very fast in first $24 \mathrm{~h}$ compared to that of exceeding reaction time $(>24 \mathrm{~h})$. The higher the reaction time lead to the higher THM concentrations which were very prominent at higher chlorine dosages. DCBM, BF and DBCM concentrations were nearly independent of reaction time for more than $24 \mathrm{~h}$ for each considered chlorine dosages. The values of THMFP showed increasing pattern with increasing dosages.

The values of THMFP showed the ascending trend from Jan. to June with the exception of Feb. proving that increased temperature enhances the THMFP concentrations. The concentrations of chloroform in May and June were found to be two times higher than those in Jan. In April, May, and June, higher values of THMFP might be due to the incorporation of bromine into organic matter and reduction of TOC in the treated water. With the increase in the chlorine dosage, the values of THMFP increased as the TOC increased from Jan. to June with the exception of Feb.

\section{Acknowledgement}

NDM is thankful to the staff of the Ganga Barrage Water Treatment Plant, Kanpur (India) for assisting in the collection of water samples.

\section{References}

1. Mughal F H, J Environ Patho Toxicol Oncol., 1992, 11(5-6), 287-292.

2. U.S, NCI, Report on the Carcinogenesis Bioassay of chloroform (CAS No.67-66-3), TR-000, NTIS Rpt. No. PB264018. Bethesda MD, National Cancer Institute, 1976. 
3. Elshorbagy W A, J Water Resources Planning Manage., 2000, 126(1), 21-28.

4. Melnick R L, Dunnick J K, Sandler D P, Elwell M R and, Barrett J C, Environ Health Persp., 1994, 102(6-7), 586-588.

5. Cantor Kenneth P, Lynch Charks F, Hildesheim Mariana, Dosemeci Mustafa, Lubin Jay, Alavanja Michael and Craun Gunther, Epidemiol., 1998, 9(1), 21-28.

6. Bove F J, Fulcomer M C, Klotz J B, Esmart J, Dufficy E M and Savrin J E, Am J Epidemiol.,1995, 141(9), 850-862.

7. $\quad$ Kallen B A J and Robert E, Reprod Toxicol., 2000, 14(4), 303-309.

8. Collins M R, Amy G L and King P H, J Environ Engg., 1985, 111(6), 850-864.

9. Urano K, Wada H and Takemasa T, Water Res., 1983, 17(12), 1797-1802.

10. Galapate R P, Kitanaka A, Ito K and Okada M, Water Sci Tech., 1997, 35(8), 15-20.

11. Chu H P and Li X Y, Membrane bioreactor for pretreatment of contaminated water supplies. In: Proceedings of $3^{\text {rd }}$ World Water Congress of the International Water Association. Melbourne, Australia, 7-12 April 2002.

12. Galapate R P, Baes A U, Ito K, Iwase K and Okada M, Water Res., 1996, 33(11), 2555-2580.

13. Rebhun M, Heller-Grossman L and Manka J, Water Environ Res., 1997, 69(6), 1154-1162.

14. Wang Z S and Liu W J, Treatment of Slightly Contaminated Drinking Water Source. (in Chinese) China Architecture Industrial Press. Beijing, 1999.

15. Rook J J, J Am Water Works Assoc., 1976, 68(3), 168-172.

16. Oliver B G and Shindler D B, Environ Sci Tech., 1980, 14(12), 1502-1505.

17. El-Rehaili A M and Weber Jr W J, Water Res., 1987, 21(5), 573-582.

18. Elshorbagy W E, Abu-Qdais H and Elsheamy M K, Water Res., 2000, 34(13), 3431-3439.

19. Fabris R, Chow C W K, Drikas M and Eikebrokk B, Water Res., 2008, 42, 4188-4196.

20. Sharp E I, Parsons S A and Jefferson B, Sci Total Environ., 2006, 363(1-3), 183-194.

21. Smith E and Kamal Y, Water Sci Technol.; Water Supply, 2009, 9(2), 191-198.

22. Marhaba T F and Van D, Advances Environ Res., 1999, 3, 255-268.

23. Marhaba T F and Van D, J Hazard Mat., 2000, A74(3), 133-147.

24. Xia Q, Chen Y Q, Wu S Z, Guo X Y and Liu J, The Guide for Chinese Surface Water Environment Standard. Chinese Environmental Science Publishing, Beijing, 2000.

25. Yoon J, Choi Y, Cho S and Lee D, Sci Total Environ., 2003, 302(1-3), 157-166.

26. Zhao Z Y, Gu J D, Fan X J and Li H B, J Hazard Mat., 2006, B134(1-3), 60-66.

27. Xue S, Wang K, Zhao Q L and Liang L, Desalination, 2009, 249(1), 63-71.

28. Chen B, Nam S N, Westerhoff P K, Krasner S W and Amy G, Water Res., 2009, 43(6), 1755-1765.

29. Bersillon J L, Acta Hydrochem Hydrobiol., 1999, 27(2), 98-100.

30. Richardson S D, Plewa M J, Wagner E D, Schoeny R and DeMarini D M, Mutation Research/Reviews Mutation Res., 2007, 636(1-3), 178-242.

31. WHO, Guidelines for Drinking Water Quality, 2011, 4, 427.

32. Dojilido J, Zbiec E and Swietlik R, Water Res., 1999, 33(14), 3111-3118.

33. Rodriguez M J, Serodes J B and Levallois P, Water Res., 2004, 38(20), 4367-4382.

34. Owen D M, Amy G L, Chowdhury Z K, Paode R, McMoy G and Viscosil K, J Am Water Works Assoc., 1995, 87(1), 4663.

35. Chang E E, Lin Y P and Chiang P C, Chemosphere, 2001, 43(8), 1029-1034.

36. American Public Health Association (APHA), Standard methods for the examination of water and wastewater.1998, 20. 